\title{
Dendritic Architecture of Principal Basolateral Amygdala Neurons Changes Congruently with Endocrine Response to Stress
}

\author{
Akshaya Hegde, Poh Soh Yee and Rupshi Mitra * \\ School of Biological Sciences, Nanyang Technological University, 60 Nanyang Drive, Singapore 637551, \\ Singapore; akshaya@resilieo.com (A.H.); joeypohsohyee@gmail.com (P.S.Y.) \\ * Correspondence: rmitra@ntu.edu.sg; Tel.: +65-6513-8043; Fax: +65-6791-1604
}

Received: 12 June 2017; Accepted: 4 July 2017; Published: 14 July 2017

\begin{abstract}
Animals cope with changing environments through changes in behavior. Such plasticity is, however, marked by substantial inter-individual variability. Neuroendocrine reactivity to challenging environments can be an important predictor of resilience. Both basolateral amygdala (BLA) neurons and adrenal glucocorticoid signaling are integral parts of the stress neuroendocrine response. In this report, we test if individual variation in hormonal response to stress is associated with individual variation in the dendritic complexity of BLA neurons. We report a positive correlation between inter-individual variability in glucocorticoid response and neuronal plasticity in the BLA subsequent to a stressor. This suggests that stressful experiences in the past act as significant sculptors of BLA neuronal plasticity and congruent neuroendocrine response.
\end{abstract}

Keywords: anxiety; corticosterone; inter-individual variation; amygdala; neuroendocrine; predator stress

\section{Introduction}

Animals frequently respond to changes in the environment by changing their endocrine milieu. For example, episodic environmental challenges lead to a rise in adrenal hormones, including glucocorticoids [1]. This rise leads to the realignment of physiological resources towards more immediate needs of coping and survival, commonly known as a flight-or-fight response [2,3]. Different species show large variation in reactivity of endocrine change, or correspondence between environmental challenge and endocrine change [4,5]. Species endemic to predictable environments exhibit less reactivity, and species with more variable ecologies exhibit tighter coupling of environmental conditions with endocrine change [6-8]. Interestingly, individuals within the same population also exhibit remarkable variation in endocrine reactivity $[4,5,9,10]$. The coefficient of variation for glucocorticoid response to a threatening environment lies at $98 \%$ for the data presented in this report. Such large variation is consistent with previously published reports and meta-analyses conducted in a variety of animals. For example, meta-analytic estimates for the coefficient of variation at 30 to $60 \mathrm{~min}$ after restraint stress range from $50 \%$ to $60 \%$ in a variety of animals [4]. These numbers suggest that, generally, a large number of individuals exhibit significant departures from mean glucocorticoid response of the group. Biological underpinnings of such large inter-individual variation remain understudied at the present.

Exposure to traumatic and/or chronic stress often leads to increased anxiety-like behavior in rodents. The anxiogenic effect of prior stress has been confirmed in a variety of paradigms, including chronic restraint [11-13], acute immobilization [14], and exposure to predators [15,16]. Increased anxiety-like behavior in these experiments is long-lasting for weeks after termination of the stress. Stress also causes long-lasting neuroendocrine changes in parallel to sustained anxiogenesis. On one hand, historically stressful episodes potentiate the endocrine response to subsequent stressors $[9,17,18]$; while 
on the other hand, stress initiates structural plasticity in the basolateral amygdala (BLA). This plasticity is characterized by dendritic hypertrophy [19] and increase in spine density [20] of principal projection neurons within the BLA.

Several strands of evidence suggest that the effects of stress on anxiety-like behavior, BLA dendrites, and adrenal hormones are not isolated biological entities. Rather, these effects likely represent nodes of a reciprocally interacting loop. For example, exogenous corticosterone treatment after cat exposure leads to greater anxiety in rats when measured after several days [9]. This anxiogenesis manifests as a lower exploration of open spaces in elevated plus mazes and greater acoustic startle. This is congruent with the ability of exogenous corticosterone to increase anxiety-like behavior by itself, in parallel to causing dendritic hypertrophy in the BLA [21]. Similarly, pharmacological blockade of steroidogenesis in rats prevents a rise in anxiety-like behavior after exposure to cat odor [22]. Molecular studies also support the notion that the BLA is crucial for the relationship between glucocorticoids and stress-induced anxiogenesis. For example, diversion of glucocorticoid signaling within the BLA from glucocorticoid receptors toward mineralocorticoid receptors [23] or towards estrogen receptors [24] reduces anxiety-like behavior. Moreover, experimental manipulations that reduce BLA hypertrophy also show concomitantly reduced anxiety-like behavior and reduced glucocorticoid levels [25-27].

These observations suggest that BLA hypertrophy, anxiety and hypercortisolism are part of an interacting triad that is facilitated by historical stress. This hypothesis predicts a positive relationship of BLA dendrites with anxiety-like behavior and/or glucocorticoid levels. An alternative interpretation is also possible. The observations above could be similarly explained if BLA dendritic hypertrophy were a compensatory response to mediators of anxiety-like behavior and/or endocrine activation. This hypothesis predicts a negative relationship between BLA dendrites and anxiety-like behavior and/or hormonal measures. We test these competing predictions in the present report by quantifying correlations between endpoints related to anxiety-like behavior, BLA plasticity and glucocorticoids within the same cohort of individual rats. This experimental design also encapsulates inter-individual variation for glucocorticoid response to novel stressful episodes subsequent to historical stressors, and the relationship of this inter-individual variation with that of the BLA dendritic structure.

\section{Materials and Methods}

\subsection{Animals and Experimental Groups}

Adult male Wistar rats (7 weeks old, weight: $220-250 \mathrm{~g}$, housed as 2 rats/cage; ad-libitum food and water; 12:12 light-dark cycles with lights on at $700 \mathrm{~h}$ ) were procured from National University of Singapore. This outbred strain was chosen because of its greater phenotypic variability for later correlational analysis. Rats were habituated for one week before the start of the experiments. All experimental procedures were reviewed and approved by the institutional animal use and care committee of Nanyang Technological University (IACUC: A-0195). The experimental sequence is depicted in Figure 1. 
A

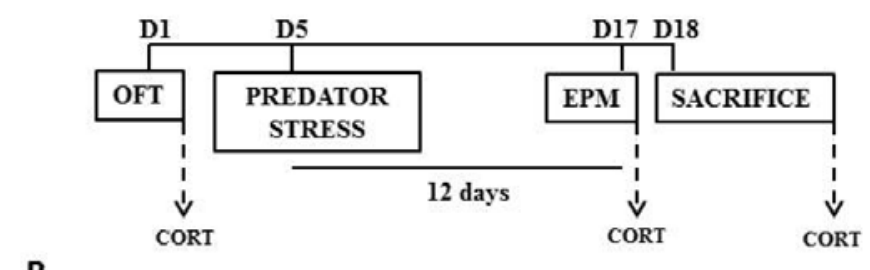

B

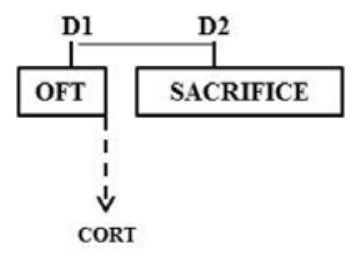

Figure 1. Schematic of experimental flow. (A) Animals were sequentially tested for anxiety in the open-field arena (OFT), exposed to predator stress and subsequently exposed to an elevated plus maze (EPM). Blood for corticosterone estimates was drawn thirty minutes after OFT, EPM, and the animals were eventually sacrificed for morphological endpoints. Days elapsed from the start of the experiment are denoted on top. (B) A separate cohort was exposed to open field and sacrificed the next day for morphological endpoints. Blood was collected $30 \mathrm{~min}$ after OFT for hormone measurement.

\subsection{Open Field Test (OFT)}

Animals were tested for anxiety-like behavior in an open field. Exposure to open field occurred before exposure to the stressor, i.e., before exposure to cat odor (Figure 1A). In addition, a separate cohort of animals was exposed to OFT without subsequent stress exposures (Figure 1B). A square-shaped open field was constructed from Plexiglas $(100 \mathrm{~cm} \times 100 \mathrm{~cm}, 30 \mathrm{~cm}$ wall $)$ and illuminated at the center (10 lux at center and 3-4 lux at the periphery). All tests were conducted between 900 and $1200 \mathrm{~h}$ (duration $=300 \mathrm{~s}$ ). Time spent in the central part of the open field $(33 \mathrm{~cm} \times 33 \mathrm{~cm})$ was measured as a proxy for lower anxiety-like behavior.

\subsection{Predator Odor Exposure}

Rats were exposed to $2 \mathrm{~mL}$ bobcat urine on day 5 of the experimental sequence (Figure 1A). The predator odor served as a stressor in our experiment [28-31]. Effect of predator odor stress on the subsequent reactivity of endocrine response and anxiety-like behavior was later measured in the elevated plus maze on day 17 Figure 1A. Exposure to predator odor occurred in a rectangular arena (two $76 \mathrm{~cm} \times 9 \mathrm{~cm}$ bisects separated by a $9 \mathrm{~cm} \times 9 \mathrm{~cm}$ central connector, wall $=15 \mathrm{~cm}$; duration $=10 \mathrm{~min}$ ). Individuals were habituated to the arena for $10 \mathrm{~min}$ on three successive days before actual exposure to the predator odor (bobcat urine). Aversion to the bobcat urine was quantified as occupancy of the bisect containing odor $(76 \mathrm{~cm} \times 9 \mathrm{~cm}$ ) relative to the total area of the arena (chance $=47.2 \%$, based on the area of the bisect containing predator odor vis-à-vis total area of the arena).

\subsection{Elevated Plus Maze (EPM)}

Animals were exposed to an EPM on day 17 of the experimental sequence (Figure 1A), between 900 and $1200 \mathrm{~h}$, trial duration = $300 \mathrm{~s}$ ). Relative open-arm exploration in the EPM was measured as a proxy for lower anxiety. The EPM consisted of two open $(75 \mathrm{~cm} \times 11 \mathrm{~cm}$, illuminated $<5$ lux $)$ and two enclosed $(75 \mathrm{~cm} \times 11 \mathrm{~cm}$, non-illuminated) arms. The maze was elevated at a height of $60 \mathrm{~cm}$ from the ground. 


\subsection{Morphological Analysis of BLA Neurons}

One day after EPM, brains were harvested after sacrifice by rapid decapitation (Figure 1A). Golgi staining was performed using commercially available reagents (FD Neurotechnologies, Columbia, MD, USA). Brain sections spanning the BLA between bregma of -2.04 and -3.36 were collected, counterstained with cresyl violet and cover-slipped in non-aqueous medium. Camera Lucida tracings of BLA neurons were produced using $400 \times$ magnification (Olympus B $\times 43$, Tokyo, Japan). Pyramidal or modified pyramidal spiny projection neurons of BLA were chosen [32] through random sampling within the BLA (Figure 2). Inclusion criteria included uniform impregnation of stain, un-truncated dendrites, and absence of visual interference from overlapping neurons. Tracings were digitized (8-bit grayscale TIFF, $300 \mathrm{dpi}$ ) for subsequent computerized image-analysis using custom-designed macros operating within ImageJ (http:/ / rsb.info.nih.gov/ij/). Dendritic length and branch points were enumerated in eight neurons per animal, and the median of eight neurons was used for subsequent correlational analysis. A sampling of eight neurons per animal provided a stable estimate of median within each individual animal, as determined by the jackknife resampling model. Dendritic spines were manually counted at $1000 \times$ magnification, using oil-immersion objective lens. Dendrites directly originating from the cell soma were classified as primary dendrites, and those originating from primary dendrites were classified as secondary dendrites. Starting from the origin of the branch, and continuing away from the cell soma, spines were counted along a $60 \mu \mathrm{m}$ stretch of the dendrite.

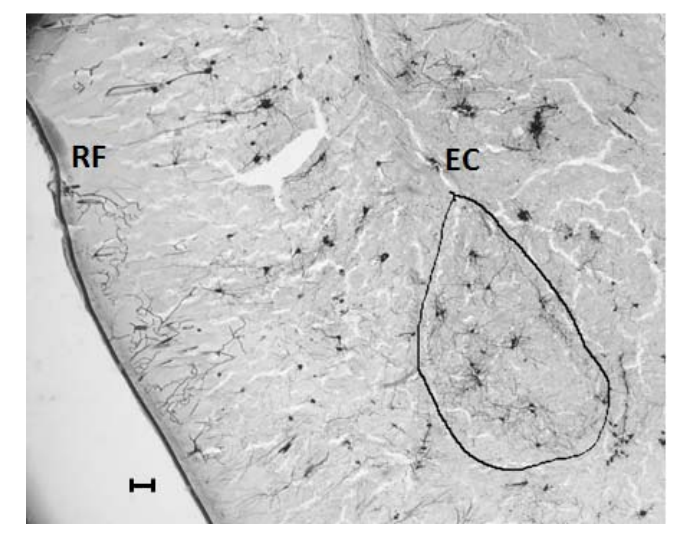

Figure 2. The region of interest sampled for dendritic arbors and spine density of the BLA neurons (bounded by black outline). RF denotes the location of the rhinal fissure, and EC denotes the location of the external capsule. The dorsal surface is towards the top of the figure and the medial surface is towards the right. Scale bar $=100 \mu \mathrm{m}$ ).

\subsection{Corticosterone Estimation}

Venous blood was collected via tail nicks at two points during the experiment (Figure 1A): before exposure to predator odor (i.e., $30 \mathrm{~min}$ post-OFT), and after EPM (i.e., $30 \mathrm{~min}$ post-EPM), subsequent to exposure to predator odor. Additionally, trunk blood was collected at the point of sacrifice. A separate cohort was used to collect blood at $30 \mathrm{~min}$ post-OFT without subsequent exposure to predator odor or EPM (Figure 1B). The concentration of serum corticosterone was quantified using a commercial enzyme-linked immunoassay (Assay Designs; Enzo ${ }^{\circledR}$ Life Sciences, Farmingdale, NY, USA).

\subsection{Statistical Analysis}

Spearman's rank correlation coefficients were calculated for pairs of experimental endpoints. A $p$ value $\leq 0.05$ was deemed as the cut-off for statistically significant correlations. $\mathrm{N}$ is listed in Tables 1 and 2. Additionally, principal component analysis was performed to delineate patterns of correlation in the observed dataset. Software IBM SPSS Statistics v23 (IBM, Armonk, NY, USA) was used for all statistical analysis. 
Table 1. Sample statistics for endpoints measured in this study.

\begin{tabular}{|c|c|c|c|c|c|c|c|c|c|c|}
\hline Estimates & $\begin{array}{l}\text { Center Time } \\
\text { in Open } \\
\text { Field }\end{array}$ & $\begin{array}{l}\text { Median } \\
\text { Dendritic } \\
\text { Length (in } \\
\text { Microns) }\end{array}$ & $\begin{array}{l}\text { Median } \\
\text { Number of } \\
\text { Branch } \\
\text { Points }\end{array}$ & $\begin{array}{l}\text { Median Spines } \\
\text { on Primary } \\
\text { Dendrites (per } \\
60 \text { Microns) }\end{array}$ & $\begin{array}{l}\text { \% Open } \\
\text { Arm Time } \\
\text { in EPM }\end{array}$ & $\begin{array}{l}\text { \% Open } \\
\text { Arm Entries } \\
\text { in EPM }\end{array}$ & $\begin{array}{l}\text { Number of } \\
\text { Enclosed } \\
\text { Arm Entries } \\
\text { in EPM }\end{array}$ & $\begin{array}{l}\text { Corticosterone } \\
\text { Post Open } \\
\text { Field (pg/mL) }\end{array}$ & $\begin{array}{l}\text { Corticosterone } \\
\text { Post EPM } \\
\text { (pg/mL) }\end{array}$ & $\begin{array}{l}\text { Corticosterone } \\
\text { Post Sacrifice } \\
\text { (pg/mL) }\end{array}$ \\
\hline Median & 3.50 & 1529 & 14.5 & 19.75 & 7.33 & 27.27 & 7 & 14.10 & 35.20 & 48.50 \\
\hline Range & 12 & 499 & 4.5 & 9.50 & 40.33 & 46.67 & 7 & 38.40 & 194.10 & 151.10 \\
\hline Mean & 4.90 & 1581 & 14.5 & 21.13 & 14.52 & 24.86 & 6 & 18.09 & 57.64 & 62.38 \\
\hline SEM & 1.269 & 55 & 0.5 & 1.25 & 4.77 & 4.76 & 1 & 4.17 & 18.56 & 14.81 \\
\hline $\mathrm{N}$ & 10 & 10 & 10 & 8 & 9 & 9 & 9 & 10 & 10 & 10 \\
\hline
\end{tabular}

Table 2. Spearman's rank correlation coefficients for endpoint pairs. The number of animals and $p$ values are also listed. Shaded cells depict endpoint pairs with statistically significant correlation.

\begin{tabular}{|c|c|c|c|c|c|c|c|c|c|c|}
\hline & & $\begin{array}{l}\text { Median } \\
\text { Dendritic } \\
\text { Length (in } \\
\text { Microns) }\end{array}$ & $\begin{array}{c}\text { Median } \\
\text { Number of } \\
\text { Branch } \\
\text { Points }\end{array}$ & $\begin{array}{c}\text { Median Spines on } \\
\text { Primary Dendrites } \\
\text { (per } 60 \text { Microns) }\end{array}$ & $\begin{array}{c}\text { \% Open } \\
\text { Arm Time } \\
\text { in EPM }\end{array}$ & $\begin{array}{c}\text { \% Open } \\
\text { Arm Entries } \\
\text { in EPM }\end{array}$ & $\begin{array}{c}\text { Number of } \\
\text { Enclosed Arm } \\
\text { Entries in EPM }\end{array}$ & $\begin{array}{l}\text { Corticosterone } \\
\text { Post Open } \\
\text { Field (pg/mL) }\end{array}$ & $\begin{array}{l}\text { Corticosterone } \\
\text { Post EPM } \\
\text { (pg/mL) }\end{array}$ & $\begin{array}{l}\text { Corticosterone } \\
\text { Post Sacrifice } \\
\text { (pg/mL) }\end{array}$ \\
\hline \multirow{3}{*}{$\begin{array}{l}\text { Center Time in Open } \\
\text { Field }\end{array}$} & Coefficient & 0.216 & 0.013 & 0.216 & -0.616 & -0.809 & -0.562 & -0.370 & -0.191 & 0.179 \\
\hline & Sig. & 0.549 & 0.973 & 0.607 & 0.077 & 0.008 & 0.115 & 0.292 & 0.596 & 0.621 \\
\hline & $\mathrm{N}$ & 10 & 10 & 8 & 9 & 9 & 9 & 10 & 10 & 10 \\
\hline \multirow{3}{*}{$\begin{array}{l}\text { Median Dendritic } \\
\text { Length (in microns) }\end{array}$} & Coefficient & & -0.067 & 0.623 & -0.200 & -0.017 & -0.280 & 0.418 & -0.224 & -0.321 \\
\hline & Sig. & & 0.853 & 0.099 & 0.606 & 0.966 & 0.466 & 0.229 & 0.533 & 0.365 \\
\hline & $\mathrm{N}$ & & 10 & 8 & 9 & 9 & 9 & 10 & 10 & 10 \\
\hline \multirow{3}{*}{$\begin{array}{l}\text { Median Number of } \\
\text { Branch Points }\end{array}$} & Coefficient & & & 0.370 & 0.101 & 0.097 & 0.185 & 0.301 & 0.638 & 0.190 \\
\hline & Sig. & & & 0.367 & 0.795 & 0.803 & 0.635 & 0.399 & 0.047 & 0.599 \\
\hline & $\mathrm{N}$ & & & 8 & 9 & 9 & 9 & 10 & 10 & 10 \\
\hline \multirow{3}{*}{$\begin{array}{c}\text { Median Spines on } \\
\text { Primary Dendrites } \\
\text { (per } 60 \text { microns) }\end{array}$} & Coefficient & & & & 0.360 & -0.306 & 0.248 & 0.108 & 0.719 & 0.503 \\
\hline & Sig. & & & & 0.427 & 0.504 & 0.592 & 0.799 & 0.045 & 0.204 \\
\hline & $\mathrm{N}$ & & & & 7 & 7 & 7 & 8 & 8 & 8 \\
\hline \multirow{3}{*}{$\begin{array}{c}\% \text { Open Arm Time in } \\
\text { EPM }\end{array}$} & Coefficient & & & & & 0.460 & 0.856 & 0.133 & 0.633 & 0.483 \\
\hline & Sig. & & & & & 0.213 & 0.003 & 0.732 & 0.067 & 0.187 \\
\hline & $\mathrm{N}$ & & & & & 9 & 9 & 9 & 9 & 9 \\
\hline
\end{tabular}


Table 2. Cont.

\begin{tabular}{|c|c|c|c|c|c|c|c|c|c|c|}
\hline & & $\begin{array}{c}\text { Median } \\
\text { Dendritic } \\
\text { Length (in } \\
\text { Microns) }\end{array}$ & $\begin{array}{c}\text { Median } \\
\text { Number of } \\
\text { Branch } \\
\text { Points }\end{array}$ & $\begin{array}{c}\text { Median Spines on } \\
\text { Primary Dendrites } \\
\text { (per } 60 \text { Microns) }\end{array}$ & $\begin{array}{l}\text { \% Open } \\
\text { Arm Time } \\
\text { in EPM }\end{array}$ & $\begin{array}{l}\text { \% Open } \\
\text { Arm Entries } \\
\text { in EPM }\end{array}$ & $\begin{array}{c}\text { Number of } \\
\text { Enclosed Arm } \\
\text { Entries in EPM }\end{array}$ & $\begin{array}{l}\text { Corticosterone } \\
\text { Post Open } \\
\text { Field (pg/mL) }\end{array}$ & $\begin{array}{l}\text { Corticosterone } \\
\text { Post EPM } \\
\text { (pg/mL) }\end{array}$ & $\begin{array}{l}\text { Corticosterone } \\
\text { Post Sacrifice } \\
\text { (pg/mL) }\end{array}$ \\
\hline \multirow{3}{*}{$\begin{array}{l}\text { \% Open Arm Entries } \\
\text { in EPM }\end{array}$} & Coefficient & & & & & & 0.460 & 0.477 & -0.008 & -0.351 \\
\hline & Sig. & & & & & & 0.213 & 0.194 & 0.983 & 0.354 \\
\hline & $\mathrm{N}$ & & & & & & 9 & 9 & 9 & 9 \\
\hline \multirow{3}{*}{$\begin{array}{l}\text { Number of Enclosed } \\
\text { Arm Entries in EPM }\end{array}$} & Coefficient & & & & & & & -0.068 & 0.525 & 0.475 \\
\hline & Sig. & & & & & & & 0.862 & 0.146 & 0.197 \\
\hline & $\mathrm{N}$ & & & & & & & 9 & 9 & 9 \\
\hline \multirow{3}{*}{$\begin{array}{l}\text { Corticosterone Post } \\
\text { Open Field (pg/mL) }\end{array}$} & Coefficient & & & & & & & & -0.079 & -0.418 \\
\hline & Sig. & & & & & & & & 0.829 & 0.229 \\
\hline & N & & & & & & & & 10 & 10 \\
\hline \multirow{3}{*}{$\begin{array}{l}\text { Corticosterone Post } \\
\text { EPM }(\mathrm{pg} / \mathrm{mL})\end{array}$} & Coefficient & & & & & & & & & 0.685 \\
\hline & Sig. & & & & & & & & & 0.029 \\
\hline & $\mathrm{N}$ & & & & & & & & & 10 \\
\hline
\end{tabular}




\section{Results}

Ten male rats were tested for pre-stress anxiety-like behavior in OFT, exposed to predator odor stress, and tested for post-stress anxiety-like behavior in EPM (Figure 1A). Congruent with previous studies [28-31], rats exhibited significant aversion to bobcat odor (Figure 3; one-sample $t$-test with chance level of $47.2 \%, t_{9}=-4.58, p=0.001$ ). Out of ten animals, post-stress anxiety-like behavior in EPM could not be measured in one animal, and spine density of BLA neurons could not be measured in two animals, due to procedural failures. The sample size available for subsequent analysis is listed in Table 1. In addition, Table 1 depicts sample statistics for all endpoints in these animals, including estimates of mean, standard error of mean, median, and range. Aversion to predator odor did not exhibit statistically significant correlations with corticosterone levels post-EPM $(p=0.80)$, median number of BLA branch points $(p=0.72)$, median spine density on primary BLA dendrites $(p=0.18)$, percentage open arm time in EPM $(p=0.67)$, or center time in open field $(p=0.50)$.

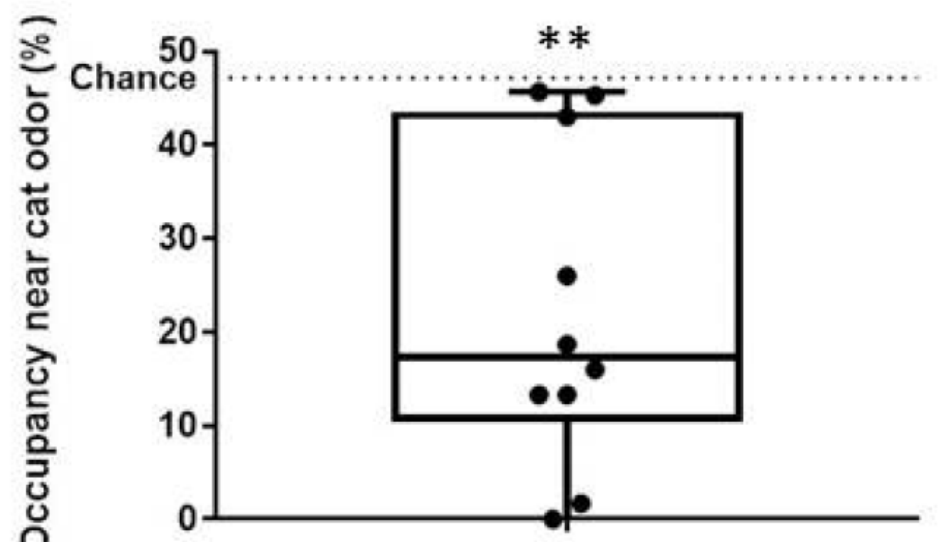

Figure 3. Aversion to bobcat urine in male rats used during the experiment. Ordinate depicts occupancy in the cat odor bisect of the arena, and the dashed line represents theoretical expectancy based on chance alone. Each dot represents the raw data from one male rat. Box plot depicts median, 25th percentile, and 75th percentile. ${ }^{* *} p<0.005$; one-sample t-test against the chance of $47.2 \%$.

A correlation matrix was calculated for pair-wise comparisons of endpoints, pertaining to anxiety-like behavior, BLA structure and corticosterone concentration using Spearman's procedure (Table 2). Concentration of plasma corticosterone thirty minutes post-EPM was positively correlated with the number of branch points of BLA neurons (Figure 4A; rho $=0.638, p \leq 0.05$ ). We further performed a linear regression between these two endpoints. Values for seven out of nine animals were constrained within the $95 \%$ confidence limit of the best linear fit (Figure 4A). Representative neurons from animals showing high and low corticosterone response post-EPM are depicted in Figure 4B. Similarly, corticosterone concentration post-EPM was also positively correlated with the number of spines on the primary shaft of BLA neurons (Figure 5; rho $=0.719, p \leq 0.05$ ). Values for six out of eight animals were constrained within $95 \%$ confidence limit of the best linear fit. 
A

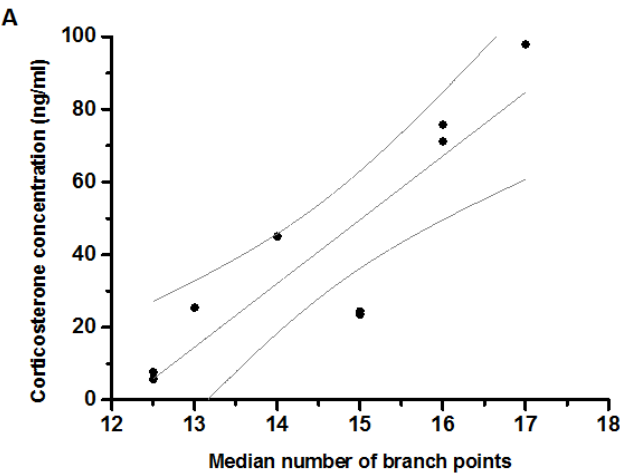

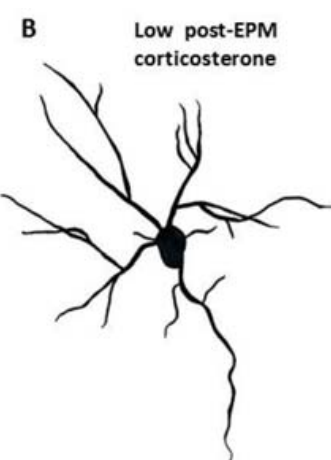

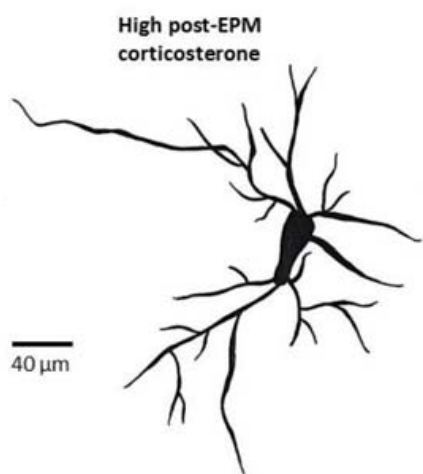

Figure 4. Correlation between branch points and corticosterone concentration. The abscissa of panel (A) depicts number of branch points per basolateral amygdala neuron (median from a sample of eight neurons sampled per animal). Ordinate depicts serum corticosterone concentration $(\mathrm{ng} / \mathrm{mL})$ thirty minutes after exposure to the elevated plus-maze. Best linear fit is also depicted with $95 \%$ confidence interval $\left(\mathrm{R}^{2}=0.75\right.$, slope $=17.5 \pm 3.5 ; \mathrm{n}=9$ animals; grey lines). Panel (B) depicts representative BLA neuronal tracings from animals exhibiting low (left, $5.7 \mathrm{ng} / \mathrm{mL}$ ) and high (right, $71.2 \mathrm{ng} / \mathrm{mL}$ ) corticosterone response post-EPM. Scale bar $=40 \mu \mathrm{m}$.

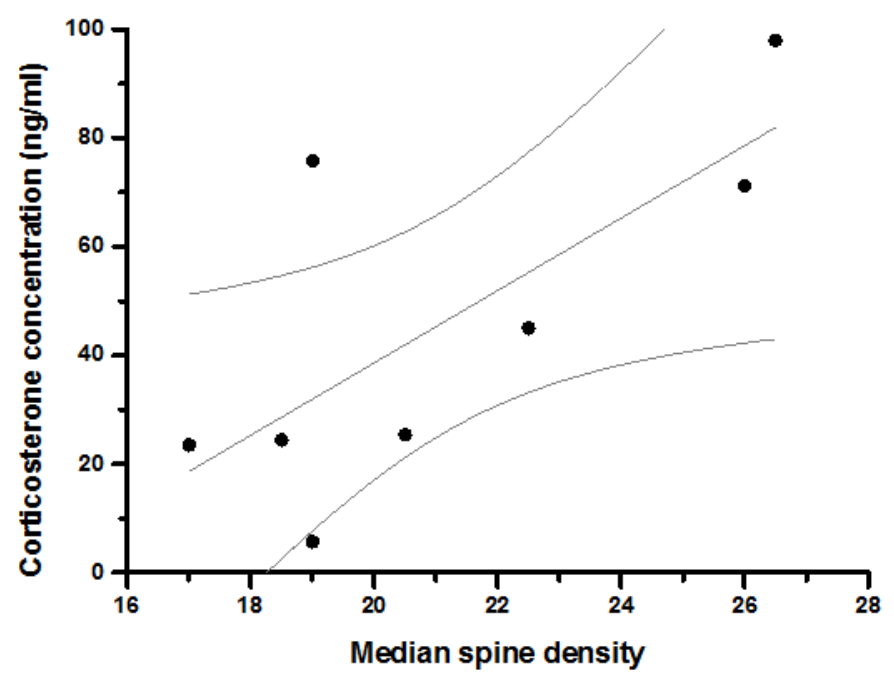

Figure 5. Correlation between spine density and corticosterone concentration. Abscissa depicts density of spines on primary shaft of basolateral amygdala neurons (median from a sample of eight neurons per animal; per $60 \mu \mathrm{m})$. Ordinate depicts serum corticosterone concentration $(\mathrm{ng} / \mathrm{mL})$ thirty minutes after exposure to the elevated plus-maze. Best linear fit is also depicted with $95 \%$ confidence interval $\left(\mathrm{R}^{2}=0.46\right.$, slope $=6.6 \pm 2.5 ; \mathrm{n}=8$ animals; grey lines $)$.

Corticosterone concentration post-EPM was positively correlated with trunk blood corticosterone obtained at the point of sacrifice. We did not observe a statistically significant correlation between corticosterone concentration post-OFT and post-EPM; collection points before and after intervening predator odor exposure (Table 2; rho $=-0.079, p=0.83, \beta$ or probability of type 2 error at accepted $\alpha$ of $0.05=0.044)$. Similarly, open arm exploration in EPM was not significantly correlated with either corticosterone concentration (Table 2; rho $=0.633$ and $-0.008, p=0.067$ and 0.98 , for $\%$ entries and time in open arm, respectively) or architecture of BLA neurons ( $r h o=0.097$ to $0.360, p=0.43$ to 0.80 ). Correlation between BLA dendritic endpoints and corticosterone concentration post-OFT (i.e., before cat odor exposure) also did not reach statistical significance. 
Principal component analysis was further used to orthogonally transform quantified endpoints. Ten endpoints related to anxiety-like behavior, BLA structure and corticosterone concentration (Figure 6) were used for dimension reduction. The principal axis method was utilized to extract the components. Only the first two principal components displayed eigenvalues greater than 2 . These two principal components extracted $65.8 \%$ of the total variance in the dataset $(36.3 \%$ and $29.6 \%$ of total variance, respectively). An endpoint was determined to load on a given component if the factor loading exceeded 0.5 for that component and was less than 0.5 for the alternative component. Using these criteria, four endpoints were found to load on the first principal component. These were post-EPM corticosterone concentration (0.913), post-sacrifice corticosterone concentration (0.923), the number of branch points on the BLA neurons (0.837), and spine density of the BLA neurons (0.731). On the other hand, three endpoints were found to load on the second principal component. These were time spent in the center of the open field (-0.901), percentage of time spent in the open arm of the EPM (0.732), and percentage of entries into the open arms of the EPM (0.897). Figure 6 depicts endpoints with references to first two principal components. When plotted this way, post-EPM and post-sacrifice corticosterone concentration loaded congruently with BLA branches and spines (Figure 6, lower right quadrant).

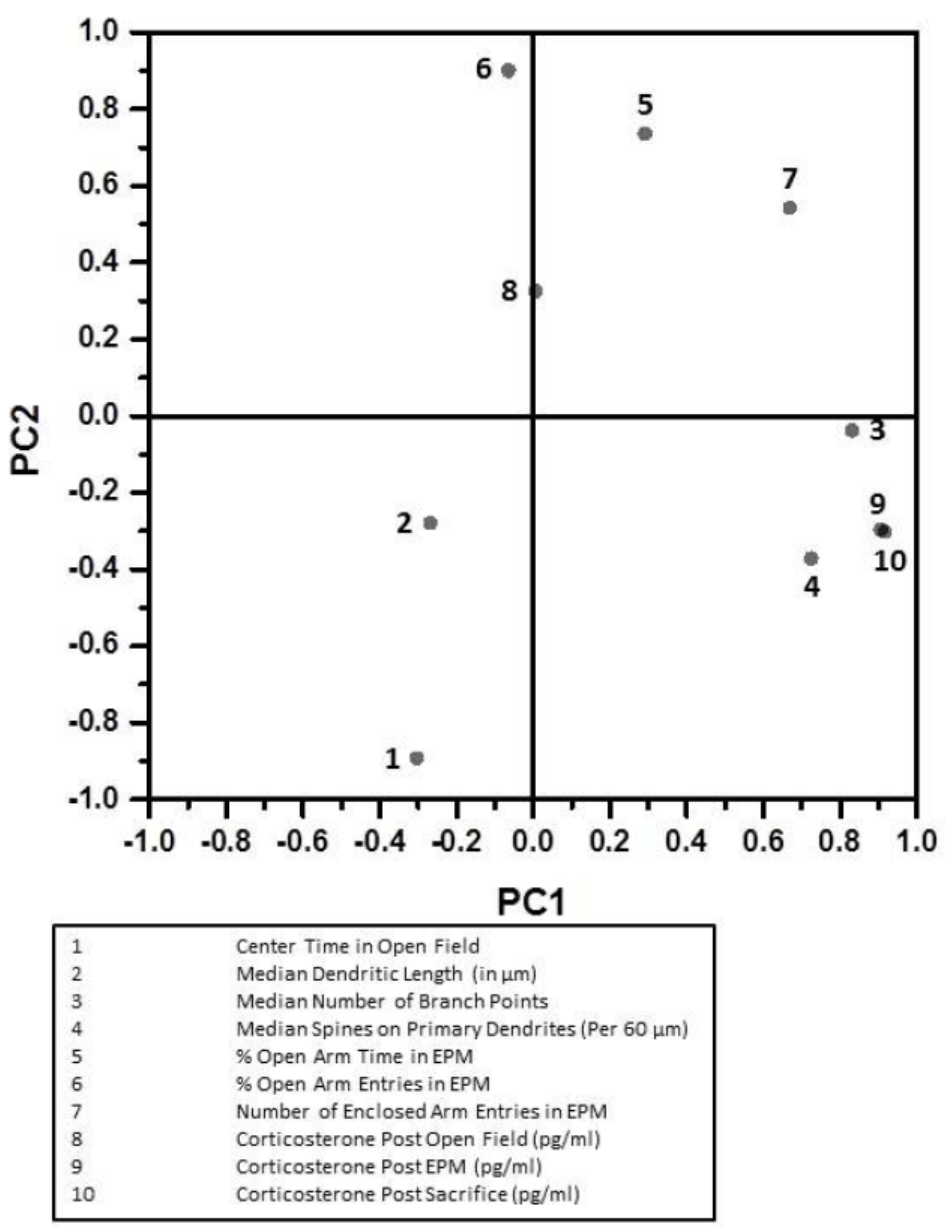

Figure 6. Principal component analysis of the measured endpoints. Initial two dimensions are depicted along abscissa and ordinate. Numerals adjacent to dots represent the endpoints, listed in the inset underneath.

A separate cohort of control male rats was exposed to a novel open field arena, followed by measurement of corticosterone and BLA dendritic measurement without intervening exposure to predator odor (Figure 1B). The concentration of plasma corticosterone post-OFT in this cohort did 
not exhibit significant correlation with dendritic length or number of branch points of BLA neurons ( $\mathrm{n}=6$ animals, rho $=-0.086, p=0.92$ ). Additionally, we did not observe a significant correlation between plasma corticosterone post-OFT and spine density on primary dendrites of BLA neurons ( $r h o=-0.486, p=0.36)$. Time spent in the anxiogenic center of the open field was not correlated with any of the dendritic measurements in the BLA $(p>0.17)$.

\section{Discussion}

In this report, we present correlative evidence that inter-individual variation in glucocorticoid levels co-elutes with variation in BLA dendritic arbors. Individuals with more complex arbors and more dendritic spines also exhibit greater post-stress levels of circulating glucocorticoids after exposure to the elevated plus-maze. This positive relationship supports the notion that BLA and glucocorticoids represent two interacting nodes of neuroendocrine plasticity in response to historical stress. In addition to positive correlation, this possibility is also supported by congruent loading of hormone levels with BLA dendritic measure during principal component analysis. Several studies have reported that experimental manipulation of BLA dendritic arbors causes a systematic change in circulating glucocorticoids. Inverse manipulation of glucocorticoids also causes systematic changes in BLA dendritic arbors. Experimental reduction in BLA activity through overexpression of $\mathrm{Ca}^{2+}$-activated $\mathrm{K}^{+}$ channels results in reduction in BLA arbors and lower glucocorticoid levels post-stress [25]. Chronic infection with a protozoan parasite Toxoplasma gondii causes dendritic atrophy in BLA and reduction in circulating glucocorticoids [27]. Polysynaptic pathways facilitate influence of the amygdala on stress endocrine axis [33]. These pathways include efferents of BLA to other brain regions, such as the central amygdala, medial amygdala, and bed nucleus of stria terminalis, which then project to the paraventricular nucleus of the hypothalamus, tapping into the stress endocrine axis. BLA neurons show activation in response to restraint stress or footshock, demonstrating that psychogenic stressors can initiate BLA activity [34-36]. On the other hand, subcutaneously supplied exogenous corticosterone causes dendritic expansion in BLA [21] similar to that observed due to stress [19,20]. Disruption of glucocorticoid binding within BLA blunts behaviors that are dependent on amygdala activity like anxiety [24] and fear conditioning [37,38]. Similarly, competitive reduction of glucocorticoid receptor binding through over-expression of mineralocorticoid receptors within BLA reduces post-stress glucocorticoid release [23]. Thus, effects of glucocorticoids on BLA arbors and effects of arbors on glucocorticoid levels are likely reciprocal parts of a syndromic and plastic response to the stress. The present study takes an inter-individual, rather than inter-group, approach to the interaction of BLA arbors and stress endocrine axis. We show that the positive relationship between these nodes remains consistent for individuals across a wide range of stress sensitivity.

Previous studies, detailed above, have established that experimental manipulations that change glucocorticoid levels also change BLA dendritic arbors. For example, stress or exogenous glucocorticoids both cause BLA dendritic expansion $[13,19,21]$. This is also supported by the observation that prenatal stress significantly increases the volume of the lateral amygdala [39] in parallel to increasing glucocorticoid levels and causing adrenal hypertrophy [40]. It remains unclear if structural plasticity in these cases represents a compensatory change, or reflects facilitation of interaction between BLA and stress hormones. Dendritic expansion can reduce input resistance of neurons, thereby increasing quiescence in reciprocal interaction with the endocrine axis. Alternatively, the addition of synaptic inputs on dendritic cables can increase the magnitude of synaptic currents, thereby facilitating the interaction. Experimental manipulations with concurrent changes in structure and hormones cannot dissect these competing possibilities. The positive correlation and congruent loading for structural and endocrine endpoints reported here argue that BLA changes do not reflect a compensatory response.

The relationship between BLA neurons and emotional resilience has been previously studied [41,42]. However, both of these reports studied rats at two extremes of anxiety-like behavior response several days after exposure to a live cat. Individual rats with greater anxiety-like behavior also exhibited greater dendritic complexity in these studies. The present study complements these 
studies through its focus on inter-individual variation along the complete parametric space available in the animal model. Our experiment also used cat urine, rather than a live cat, as the initial stressor. Cat urine is a partial predator cue which is less predictive of the cat presence and hence is less stressful [43]. Our goal in choosing this stimulus was to increase inter-individual variability available for correlational analysis.

It should be noted that the current evidence is mainly correlative in nature. For example, it can be argued that inter-individual variability in the stress endocrine axis results in variable effects of predator odor on BLA dendritic arbors. From this perspective, BLA structural plasticity and post-stress glucocorticoids can be viewed as two independent manifestations without a functional relationship. Such independence is unlikely in view of prior work showing congruence between BLA plasticity and future endocrine response during experimental manipulations. It is more parsimonious to assume that dendritic changes in the BLA and changes in post-EPM glucocorticoid levels reflect a reciprocal and functional relationship that encapsulates the effects of historical experience. Yet an unequivocal demonstration will require investigation across a wider range of phenotypic diversity, e.g., using a hybrid mouse diversity panel or collaborative crosses. We hope that the present observations will provide an impetus to these experiments in future. Conclusions drawn in this study are limited by the relatively low sample size. This may have precluded discovery of other associations that were biologically present but could not be discerned from the available statistical power of the study. This is particularly relevant to the association between dendritic arbors of the BLA and anxiety-like behavior measured in the EPM, in view of previous reports that stress concomitantly causes anxiogenesis and BLA dendritic expansion [12,19,21]. It can also be argued that association between glucocorticoid response to the EPM and the BLA structure reflects a consequence of behavioral testing rather than historical stressor of predator odor. Time elapsed between the quantification of anxiety-like behavior in plus-maze and sacrifice was short. It is unlikely that the stress of the elevated plus-maze itself resulted in structural plasticity in the BLA because these changes are known to require a chronic time-frame [20]. Nevertheless, we do not unequivocally demonstrate a lack of association between structural and endocrine endpoints in the absence of predator odor exposure.

BLA dendritic changes, especially branching of the arbors, occur over a relatively prolonged timeframe. For example, dendritic changes in the BLA due to restraint stress after a single session of acute restraint requires a chronic window of ten days to manifest and remain unobservable one day after the stress exposure [20]. Similarly, acute treatment with extraneous corticosterone leads to dendritic hypertrophy in the BLA [21]. In our present study, twenty-four hours elapsed between EPM exposure and sacrifice of the animals. Thus, it is restrictive to assume that the greater BLA dendritic complexity was associated with greater corticosterone levels after EPM, rather than greater post-EPM stress hormones leading to more complex BLA dendrites.

\section{Conclusions}

In conclusion, we report that BLA dendritic architecture varies congruently with stress hormone response to a novel stressor after exposure to predator odor. This suggests that BLA neurons are important mediators of inter-individual variation in stress-sensitivity and endocrine response to the challenging environment.

Acknowledgments: We acknowledge Archana Ashokan for help in the behavioral experiments. We thank Ajai Vyas for help with statistical analysis and script editing. This work was funded by Nanyang Technological University and Ministry of Education, Singapore (Grant \#RG46/12).

Author Contributions: Rupshi Mitra planned, designed experiments, analyzed results, and wrote the script; Akshaya Hegde and Poh Soh Yee executed experiments. Akshaya Hegde analyzed experimental results.

Conflicts of Interest: The authors declare no conflict of interest. 


\section{References}

1. Herman, J.P.; McKlveen, J.M.; Ghosal, S.; Kopp, B.; Wulsin, A.; Makinson, R.; Scheimann, J.; Myers, B. Regulation of the Hypothalamic-Pituitary-Adrenocortical Stress Response. Compr. Physiol. 2016, 6, 603-621. [PubMed]

2. Coderre, L.; Srivastava, A.K.; Chiasson, J.L. Role of glucocorticoid in the regulation of glycogen metabolism in skeletal muscle. Am. J. Physiol. 1991, 260, E927-E932. [PubMed]

3. Myers, B.; McKlveen, J.M.; Herman, J.P. Glucocorticoid actions on synapses, circuits, and behavior: Implications for the energetics of stress. Front. Neuroendocrinol. 2014, 35, 180-196. [CrossRef] [PubMed]

4. Cockrem, J.F. Individual variation in glucocorticoid stress responses in animals. Gen. Comp. Endocrinol. 2013, 181, 45-58. [CrossRef] [PubMed]

5. Cockrem, J.F.; Barrett, D.P.; Candy, E.J.; Potter, M.A. Corticosterone responses in birds: Individual variation and repeatability in Adelie penguins (Pygoscelisadeliae) and other species, and the use of power analysis to determine sample sizes. Gener. Comp. Endocrinol. 2009, 163, 158-168. [CrossRef] [PubMed]

6. Dufty, A.M.; Clobert, J.; Møller, A.P. Hormones, developmental plasticity and adaptation. Trends Ecol. Evol. 2002, 17, 190-196. [CrossRef]

7. Ricklefs, R.E.; Wikelski, M. The physiology/life-history nexus. Trends Ecol. Evol. 2002, 17, 462-468. [CrossRef]

8. Hau, M.; Ricklefs, R.E.; Wikelski, M.; Lee, K.A. Corticosterone, testosterone and life-history strategies of birds. Proc. R. Soc. Lond. B Biol. Sci. 2010, 277, 3203-3212. [CrossRef] [PubMed]

9. Adamec, R.E.; Blundell, J.; Burton, P. Relationship of the predatory attack experience to neural plasticity, pCREB expression and neuroendocrine response. Neurosci. Biobehav. Rev. 2006, 30, 356-375. [CrossRef] [PubMed]

10. Bowen, M.T.; Dass, S.A.H.; Booth, J.; Suraev, A.; Vyas, A.; McGregor, I.S. Active coping toward predatory stress is associated with lower corticosterone and progesterone plasma levels and decreased methylation in the medial amygdala vasopressin system. Horm. Behav. 2014, 66, 561-566. [CrossRef] [PubMed]

11. Mitra, R.; Vyas, A.; Chatterjee, G.; Chattarji, S. Chronic-stress induced modulation of different states of anxiety-like behavior in female rats. Neurosci. Lett. 2005, 383, 278-283. [CrossRef] [PubMed]

12. Vyas, A.; Chattarji, S. Modulation of different states of anxiety-like behavior by chronic stress. Behav. Neurosci. 2004, 118, 1450-1454. [CrossRef] [PubMed]

13. Vyas, A.; Mitra, R.; Chattarji, S. Enhanced anxiety and hypertrophy in basolateral amygdala neurons following chronic stress in rats. Ann. N. Y. Acad. Sci. 2003, 985, 554-555. [CrossRef]

14. Liang, Z.; King, J.; Zhang, N. Neuroplasticity to a single-episode traumatic stress revealed by resting-state fMRI in awake rats. NeuroImage 2014, 103, 485-491. [CrossRef] [PubMed]

15. Adamec, R.; Walling, S.; Burton, P. Long-lasting, selective, anxiogenic effects of feline predator stress in mice. Physiol. Behav. 2004, 83, 401-410. [CrossRef] [PubMed]

16. Adamec, R.E.; Blundell, J.; Collins, A. Neural plasticity and stress induced changes in defense in the rat. Neurosci. Biobehav. Rev. 2001, 25, 721-744. [CrossRef]

17. DeMaria, E.J.; Lilly, M.P.; Gann, D.S. Potentiated hormonal responses in a model of traumatic injury. J. Surg. Res. 1987, 43, 45-51. [CrossRef]

18. Lynn, S.E.; Prince, L.E.; Phillips, M.M. A single exposure to an acute stressor has lasting consequences for the hypothalamo-pituitary-adrenal response to stress in free-living birds. Gen. Comp. Endocrinol. 2010, 165, 337-344. [CrossRef] [PubMed]

19. Vyas, A.; Mitra, R.; Rao, B.S.; Chattarji, S. Chronic stress induces contrasting patterns of dendritic remodeling in hippocampal and amygdaloid neurons. J. Neurosci. 2002, 22, 6810-6818. [PubMed]

20. Mitra, R.; Jadhav, S.; McEwen, B.S.; Vyas, A.; Chattarji, S. Stress duration modulates the spatiotemporal patterns of spine formation in the basolateral amygdala. Proc. Natl. Acad. Sci. USA 2005, 102, 9371-9376. [CrossRef] [PubMed]

21. Mitra, R.; Sapolsky, R.M. Acute corticosterone treatment is sufficient to induce anxiety and amygdaloid dendritic hypertrophy. Proc. Natl. Acad. Sci. USA 2008, 105, 5573-5578. [CrossRef] [PubMed]

22. Cohen, H.; Benjamin, J.; Kaplan, Z.; Kotler, M. Administration of high-dose ketoconazole, an inhibitor of steroid synthesis, prevents posttraumatic anxiety in an animal model. Eur. Neuropsychopharmacol. 2000, 10, 429-435. [CrossRef]

23. Mitra, R.; Ferguson, D.; Sapolsky, R.M. Mineralocorticoid receptor overexpression in basolateral amygdala reduces corticosterone secretion and anxiety. Biol. Psychiatry 2009, 66, 686-690. [CrossRef] [PubMed] 
24. Mitra, R.; Sapolsky, R.M. Expression of chimeric estrogen-glucocorticoid-receptor in the amygdala reduces anxiety. Brain Res. 2010, 1342, 33-38. [CrossRef] [PubMed]

25. Mitra, R.; Ferguson, D.; Sapolsky, R.M. SK2 potassium channel overexpression in basolateral amygdala reduces anxiety, stress-induced corticosterone secretion and dendritic arborization. Mol. Psychiatry 2009, 14, 847-855. [CrossRef] [PubMed]

26. Mitra, R.; Sapolsky, R.M. Gene therapy in rodent amygdala against fear disorders. Expert. Opin. Biol. Ther. 2010, 10, 1289-1303. [CrossRef] [PubMed]

27. Mitra, R.; Sapolsky, R.M.; Vyas, A. Toxoplasma gondii infection induces dendritic retraction in basolateral amygdala accompanied by reduced corticosterone secretion. Dis. Model. Mech. 2013, 6, 516-520. [CrossRef] [PubMed]

28. Berdoy, M.; Webster, J.P.; Macdonald, D.W. Fatal attraction in rats infected with Toxoplasma gondii. Proc. R. Soc. Lond. B Biol. Sci. 2000, 267, 1591-1594. [CrossRef] [PubMed]

29. House, P.K.; Vyas, A.; Sapolsky, R. Predator cat odors activate sexual arousal pathways in brains of Toxoplasma gondii infected rats. PLoS ONE 2011, 6, e23277. [CrossRef] [PubMed]

30. Vyas, A.; Kim, S.K.; Giacomini, N.; Boothroyd, J.C.; Sapolsky, R.M. Behavioral changes induced by Toxoplasma infection of rodents are highly specific to aversion of cat odors. Proc. Natl. Acad. Sci. USA 2007, 104, 6442-6447. [CrossRef] [PubMed]

31. Xu, H.Y.; Liu, Y.J.; Xu, M.Y.; Zhang, Y.H.; Zhang, J.X.; Wu, Y.J. Inactivation of the bed nucleus of the stria terminalis suppresses the innate fear responses of rats induced by the odor of cat urine. Neuroscience 2012, 221, 21-27. [CrossRef] [PubMed]

32. McDonald, A.J. Neurons of the lateral and basolateral amygdaloid nuclei: A Golgi study in the rat. J. Comp. Neurol. 1982, 212, 293-312. [CrossRef] [PubMed]

33. Herman, J.P.; Figueiredo, H.; Mueller, N.K.; Ulrich-Lai, Y.; Ostrander, M.M.; Choi, D.C.; Cullinan, W.E. Central mechanisms of stress integration: Hierarchical circuitry controlling hypothalamo-pituitary-adrenocortical responsiveness. Front. Neuroendocrinol. 2003, 24, 151-180. [CrossRef] [PubMed]

34. Bourne, A.R.; Mohan, G.; Stone, M.F.; Pham, M.Q.; Schultz, C.R.; Meyerhoff, J.L.; Lumley, L.A. Olfactory cues increase avoidance behavior and induce Fos expression in the amygdala, hippocampus and prefrontal cortex of socially defeated mice. Behav. Brain Res. 2013, 256, 188-196. [CrossRef] [PubMed]

35. Hoffman, A.N.; Lorson, N.G.; Sanabria, F.; Olive, M.F.; Conrad, C.D. Chronic stress disrupts fear extinction and enhances amygdala and hippocampal Fos expression in an animal model of post-traumatic stress disorder. Neurobiol. Learn. Mem. 2014, 112, 139-147. [CrossRef] [PubMed]

36. Weinberg, M.S.; Grissom, N.; Paul, E.; Bhatnagar, S.; Maier, S.F.; Spencer, R.L. Inescapable but not escapable stress leads to increased struggling behavior and basolateral amygdala c-fos gene expression in response to subsequent novel stress challenge. Neuroscience 2010, 170, 138-148. [CrossRef] [PubMed]

37. Rodrigues, S.M.; LeDoux, J.E.; Sapolsky, R.M. The influence of stress hormones on fear circuitry. Annu. Rev. Neurosci. 2009, 32, 289-313. [CrossRef] [PubMed]

38. Rodrigues, S.M.; Sapolsky, R.M. Disruption of fear memory through dual-hormone gene therapy. Biol. Psychiatry 2009, 65, 441-444. [CrossRef] [PubMed]

39. Salm, A.K.; Pavelko, M.; Krouse, E.M.; Webster, W.; Kraszpulski, M.; Birkle, D.L. Lateral amygdaloid nucleus expansion in adult rats is associated with exposure to prenatal stress. Brain Res. Dev. Brain Res. 2004, 148, 159-167. [CrossRef] [PubMed]

40. Ward, H.E.; Johnson, E.A.; Salm, A.K.; Birkle, D.L. Effects of prenatal stress on defensive withdrawal behavior and corticotropin releasing factor systems in rat brain. Physiol. Behav. 2000, 70, 359-366. [CrossRef]

41. Mitra, R.; Adamec, R.; Sapolsky, R. Resilience against predator stress and dendritic morphology of amygdala neurons. Behav. Brain Res. 2009, 205, 535-543. [CrossRef] [PubMed]

42. Adamec, R.; Hebert, M.; Blundell, J.; Mervis, R.F. Dendritic morphology of amygdala and hippocampal neurons in more and less predator stress responsive rats and more and less spontaneously anxious handled controls. Behav. Brain Res. 2012, 226, 133-146. [CrossRef] [PubMed]

43. Dielenberg, R.A.; McGregor, I.S. Defensive behavior in rats towards predatory odors: A review. Neurosci. Biobehav. Rev. 2001, 25, 597-609. [PubMed]

(C) 2017 by the authors. Licensee MDPI, Basel, Switzerland. This article is an open access article distributed under the terms and conditions of the Creative Commons Attribution (CC BY) license (http://creativecommons.org/licenses/by/4.0/). 